\title{
The future of unpaid work: Estimating the effects of automation on time spent on housework and care work in Japan and the UK
}

\author{
Ekaterina Hertog, University of Oxford \\ Setsuya Fukuda, National Institute of Population and Social Security Research \\ Rikiya Matsukura, Nihon University \\ Nobuko Nagase, Ochanomizu University \\ Vili Lehdonvirta, University of Oxford
}

\begin{abstract}
Unpaid household work is vital for human reproduction and enables all other forms of work. However, debates about the "future of work" have yet to address unpaid work. In this article, we present first estimates of the impacts of "smart" and "AI" technologies on unpaid work. We ask what the likelihood is of various types of unpaid work being automated, and how this would change the time spent on domestic work and on the gendered division of labour. To achieve this, we adapt three established automation likelihood estimates for paid work occupations to estimate the automation likelihood of 19 unpaid work tasks. Applying these estimates to Japanese and UK national time use data, we find that 50-60\% of the total time spent on unpaid work could be saved through automation. The savings are unevenly distributed: a woman aged 20-59 in Japan could save over 1,000 hours per year, whereas men in the UK could save 600 hours and men in Japan only 250 hours. Domestic automation could free up to $9.3 \%$ of women in Japan and $5.8 \%$ of women in the UK to take up full- or part-time employment, pointing to substantial potential economic and social gains from domestic automation.
\end{abstract}

Keywords: unpaid work, automation, labour supply, gender equality, time use 


\section{Introduction}

Household service robots, such as robotic vacuum cleaners and floor mops, are by far the most popular type of robot today in terms of units sold (International Federation of Robotics, 2020). In 2019, 18.6 million household service robots were sold globally, compared to 173,000 professional service robots (e.g. delivery robots, cleaning and disinfection robots, medical robots), and 373,240 industrial robots (Figure 1). Households are also rapidly adopting other new labour-saving innovations, such as online grocery shopping, food delivery platforms, and children's learning apps (Ahuja, Chandra, Lord, \& Peens, 2021; Baarsma \& Groenewegen, 2021; Singer, 2021). A technological revolution appears to be underway, at least, in the world's wealthier households.

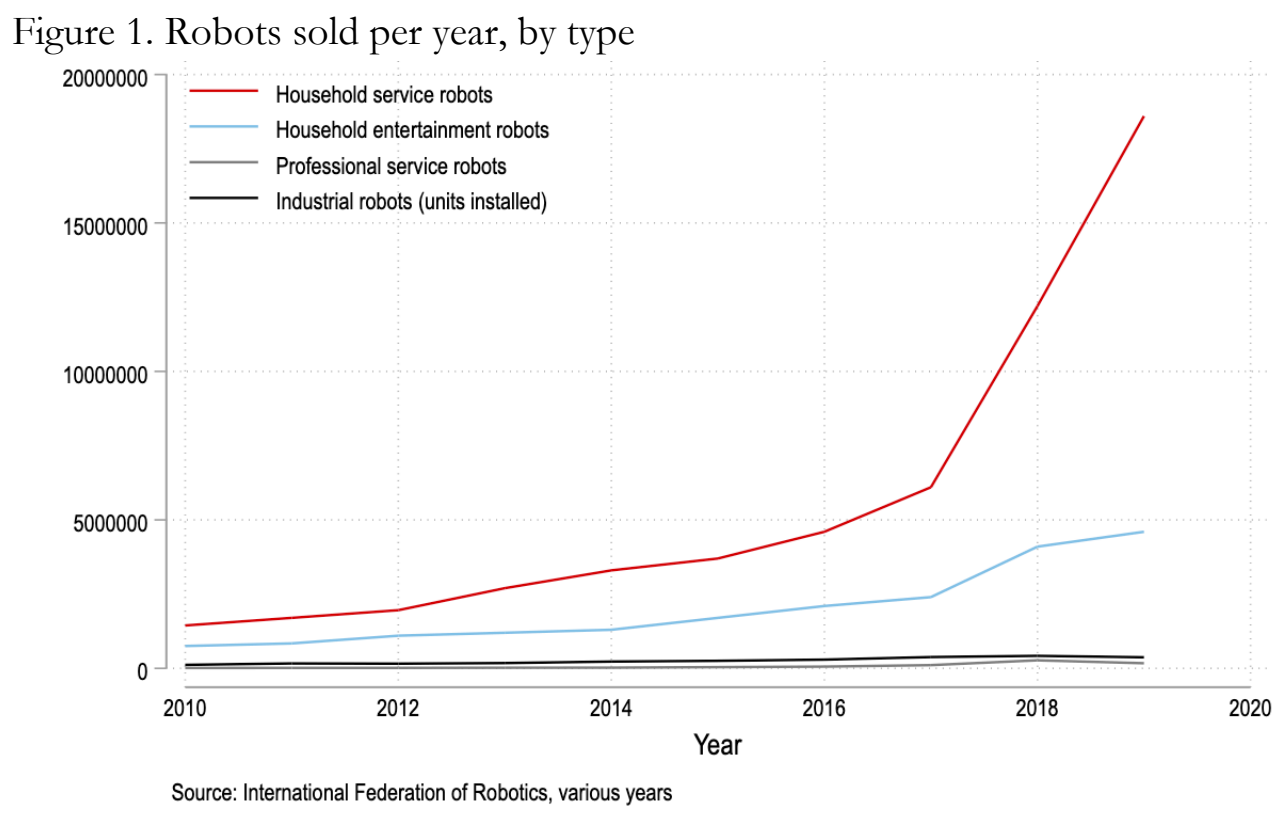

Academics and policymakers are presently paying significant attention to the consequences of adopting robots and other labour-saving technologies for the future of paid employment (Frey \& Osborne, 2017; Autor et al., 2003; Goos and Manning, 2007). By contrast, new technologies' implications for the future of unpaid housework and care work have received little attention. The value of unpaid domestic labour is not included in gross domestic product (GDP) or national income accounting indicators, which makes it largely invisible. Yet societies could not function if meals were not cooked, houses were not cleaned, and children and dependent adults were not cared for. Gershuny (2018) estimates that working-age adults in high-income countries currently spend a daily average of 250-300 minutes on paid work and 180-250 minutes on unpaid domestic work. If new technologies reduced the time spent on unpaid work, the social and economic implications could be enormous.

At present, unpaid work falls very unequally between genders. Working-age women across high-income countries do at least $60 \%$ of all unpaid work and in the majority of countries their share is larger (Gershuny, 2018, p.2). This inequality increases as men and women become parents, and persists into old age (Pailhé et al., 2021). More time devoted to unpaid work means less time for other things. Women spend less time in paid work, which contributes to a persistent 
gender wage gap (Goldin, 2014; Ruppanner, 2020). Automation of unpaid work could thus both alleviate gender inequality and increase the supply of labour to the paid labour market.

Reductions in domestic workload through technology could also promote elderly independence and limit the costs of elderly care, which at present are rising precipitously in ageing postindustrial societies (Organisation for Economic Cooperation and Development, 2020).

In this paper we estimate for the first time how susceptible different unpaid work tasks are to replacement by new technologies. We do this by taking the automation probability estimates that Frey and Osborne (2017) and other researchers have developed for paid work and adapting them to unpaid work. We moreover estimate how much of women's and men's time would be freed up if unpaid work tasks were automated to their full potential, and how this could impact the supply of labour to the paid labour market.

We carry out our estimations using time use data from two high-income countries: United Kingdom and Japan. The two countries have comparable per capita GDP levels, and both are technologically advanced. Yet they offer very different cultural and demographic contexts in which people allocate time to paid and unpaid labour. The UK is a more genderequal society. In the World Economic Forum's 2020 Global Gender Gap Index, the UK was ranked $21^{\text {st }}$ out of 153 countries, while Japan was ranked 121 ${ }^{\text {st }}$ (World Economic Forum, 2019). In both countries women spend more time on domestic work compared to men while men spend more time in paid work, but in Japan the differences are considerably larger (Organisation for Economic Cooperation and Development, 2021). Both countries are ageing societies, but Japan is older and greying faster. In 2019, 28.4\% of Japan's population were aged 65 or over (Statistics Bureau, 2020, p.12), compared to 18.5\% in the UK (ONS, 2020). In 2015 the total fertility rate ${ }^{1}$ in Japan was 1.45 , compared to 1.68 in the UK. Thus, current and near future elderly care demand is greater in Japan than in the UK, while childcare demand is higher in the UK.

Our results suggest that all major domestic work activities except for childcare could be automatable with a more than $50 \%$ probability, or alternatively that more than $50 \%$ of time spent on the activity could be saved through technology. This would narrow the gender disparity in absolute time spent on domestic work but would not eliminate it. One potential implication of the time savings is greater labour market participation. Women, especially Japanese women, would benefit disproportionately in that respect. The potential number of full-time female employees in Japan could rise by about $2 \%$. Estimating potential increases in labour supply due to the automation of unpaid domestic work is a particularly relevant exercise in light of the labour force shortages currently faced by Japan and the UK.

We also find that potential labour savings and increases in labour market participation vary by age in UK and in Japan. Young children lead to particularly heavy housework and care responsibilities in both countries. In both countries, women around the age when they are likely to have young children could save the most time with the help of domestic automation. But they also have the lowest likelihood of being able to free enough time to join the labour market even after such time savings.

Actual futures depend as much on cultural values and gendered social norms as they do on technological potentials alone. But our results demonstrate the transformative potential of

\footnotetext{
${ }^{1}$ The total fertility rate (TFR) of a population is the average number of children that would be born to a woman over her lifetime if she was to experience the exact current age-specific fertility rates through her lifetime.
} 
technology within the domestic sphere if such constraints were overcome, with women in less gender-equal societies benefiting from automation the most.

\section{Background}

\subsection{The future of work}

The present debate on the future of paid work is characterized by striking predictions concerning the future effects of technologies on labour markets. In particular, a frequently cited study by Frey and Osborne (2017) concludes that as many as 47\% of all US jobs are at "high risk" of computerization within the coming decades. The prediction is based on expert estimates by a group of machine learning researchers of the automatability of the tasks that constitute various occupations. The study was widely reported in the media when first published as an online working paper in 2013 and has helped to fuel the present future of work debate. Later studies highlighted that these predictions are sensitive to model specifications (Stephany \& Lorenz, 2021) and alternative methodologies resulted in more moderate estimates. Yet even more cautious estimates, such as a study by White, Lacey, and Ardanaz-Badia (2019) who concluded that in England $7.4 \%$ of people were employed in jobs at a high risk of automation, predict substantial levels of paid work automation.

There are clear parallels between paid and unpaid labour. Unpaid domestic work is defined by the so-called "third party criterion" (Reid, 1934) which stipulates that domestic work is the sum of unpaid domestic activities that could be delegated to a paid worker or replaced by market goods. Based on this definition the same activity could be categorised as paid or unpaid labour depending on who carries it out. Yet the present debate on the future of work has focused entirely on paid work and excluded unpaid work from its predictions. We address this gap in the literature.

\subsection{Unpaid work and technology}

Scholars of previous waves of automation have observed that technologies' effects on household members' daily routines have been far from uniform (Cowan, 2012; Greenwood et al., 2005). In the first half of the $20^{\text {th }}$-century industrialisation and urbanization resulted in the rapid rise of households with electricity and running water, which revolutionised household production. Several domestic tasks hitherto largely carried out within households by women became obsolete (e.g., carrying water) or moved from home into the market (e.g., purchasing food and clothes or at least material to make clothes). The centralisation of some domestic production tasks also gave rise to new domestic responsibilities associated with getting consumer goods home. Shopping became time-consuming and was largely assumed by women (Cowan, 2012, p. 388).

The first half of the twentieth century is also the time when almost all electric domestic appliances, the "engines of liberation" (Greenwood et al., 2005) were invented. These include the vacuum cleaner (1901), the electric iron (1903), the electric washing machine (1904) the refrigerator (1913), the dishwasher (1903), the fully automatic washer-dryer (mid 1930s), and the microwave oven (1945) (Krenz \& Strulik, 2022). Initially luxury goods, these devices improved quickly and became ubiquitous in Japanese and UK households by late 1970s, changing domestic routines and reducing the total time spent on domestic work (Bowden \& Offer, 1994; Maki, 1996). 
However, from 1980s onwards, reductions in the time spent on domestic work in Japanese and UK households diminished considerably (Gershuny, Vega-Rapun, \& Lamote, 2020; Statistics Bureau, various years; Yano, 1995). Labour savings from domestic technology appeared to have plateaued.

Digital technologies aimed at facilitating work have been shown to influence domestic routines in two ways. They change individuals' experiences of the boundaries between work and family (Ollier-Malaterre, Jacobs, \& Rothbard, 2019). The rising wage gap brought about by automation has also been argued to result in a resurgence of servant economy, enabling well paid professionals to outsource their domestic work to lower-skilled humans (Krenz \& Strulik, 2022). This paper adds to this literature with an analysis of the potential direct influence of digital technologies on domestic work. Advances in robotics, computer vision, machine learning, the Internet of Things, and related technologies are associated with a new wave of domestic labour saving technologies. Marketed under such labels as "smart" and "AI", there appears to be significant pent-up consumer demand for such devices and services (Figure 1). This latest wave of domestic automation is the focus of our study.

As with previous waves, domestic tasks are likely to vary in their susceptibility to this new wave of automation. As stressed by Broussard (2018), "the machine-learning approach is great for routine tasks inside a fixed universe of symbols", indicating that machines operate well in routine, predictable, and well-indexed environments. Routinized housework, such as vacuum cleaning is therefore likely more open to automation. Algorithms to replace more creative types of housework, such as cooking from scratch, or care work tasks that involve human interaction, are probably more challenging to design. Thus, we ask:

\section{RQ1: How susceptible are different unpaid household tasks to automation?}

\subsection{Gendered implications of domestic automation}

Domestic automation affects individuals unevenly. For example, women spend more time on domestic work than men do. Thus, automation of domestic tasks, especially tasks that are dominated by women, will benefit women more than men and could reduce gender inequality in time spent on household production.

The gendered consequences are likely to vary between countries and cultural contexts. Domestic work differs in different societies. Time invested in domestic work and how it is shared between men and women within households also depends on many local factors, such as gender equality at home, the prevalence of outsourcing of domestic work tasks, the availability and affordability of institutions providing help with domestic work, such as nurseries, and so on.

Although both Japan and the UK are characterised by gender inequality in the domestic sphere, this inequality is much more pronounced in Japan. Thus we ask:

\section{RQ2: If household tasks were automated to their predicted full potential, how much time would be freed up for women and men in Japan and the UK?}

If people spent less time on housework, they could invest the time freed in many different ways. One societally important use could be a larger contribution to the paid labour market. Greenwood et al. (2005) and Cavalcanti and Tavares (2008) argue that past reductions of housework hours through domestic appliances enabled women to rival men in the paid labour 
market. Using data from 17 OECD countries, Cavalcanti and Tavares (2008) find a substantial and statistically significant increase in female labour force participation associated with reductions in the price of domestic appliances. We thus ask:

RQ3: How much could the predicted automation of household tasks increase labour supply for women and men in Japan and the UK?

\section{Research design}

We adapt three sets of automatability scores to household tasks by linking these tasks as defined in Japanese and UK time use surveys with the most similar paid work occupations. We then apply the scores to micro-level time use data from Japan and the UK to produce predictions on how future domestic automation could impact women's and men's time use and labour supply in both countries.

\subsection{Time-use Data}

We start by identifying core domestic work tasks as recorded in the UK Time Use Survey (UKTUS) 2014-15 and the Japanese Survey on Time Use and Leisure Activities (STULA) 2016. ${ }^{2}$ Both UKTUS and STULA surveys collect detailed information about individuals' time use, along with a range of social, economic, and demographic variables. Having identified time use activities relevant to unpaid domestic work from UKTUS and STULA, we harmonised them into 19 activities $^{3}$ and further grouped them into 9 broader activities as shown in Table 1.

\footnotetext{
2 Access to the UKTUS 2015 is obtained through the UK Data Archive http://doi.org/10.5255/UKDA-SN-81281. Permission to use the data on STULA 2016 was obtained through the Statistics Bureau of Japan based on the Statistics Act (Act No. 53 of 2007), Article 33 http://www.stat.go.jp/english/data/shakai/index.html. See details of both surveys in the Appendix.

${ }^{3}$ This list was informed by our interviews with automation experts (for details see Author 5 et al, 2022) as well as by the practical constraints resulting from our need to harmonise domestic work activities in UKTUS and STULA 2016 surveys.
} 
Table 1. The list of unpaid work activities, linked occupations, and automation scores

\begin{tabular}{|c|c|c|c|c|c|}
\hline \multirow{2}{*}{ Broad activity } & \multirow{2}{*}{ Activity } & \multirow{2}{*}{ Occupation } & \multicolumn{3}{|c|}{ Automation score } \\
\hline & & & $\mathrm{F} \& \mathrm{O}$ & NRI & ONS \\
\hline \multirow[t]{2}{*}{1 FOOD MANAGEMENT } & Cooking & Cooks, Bakers, Pastry chef & 0.800 & 0.458 & 0.617 \\
\hline & Dish washing & $\begin{array}{l}\text { Dish washers, Kitchen assistant, } \\
\text { Hole staff }\end{array}$ & 0.770 & 0.920 & 0.692 \\
\hline 2 HOUSEHOLD UPKEEP & Cleaning & Janitors and cleaners & 0.660 & 0.995 & 0.681 \\
\hline 3 MAKING TEXTILES & Making textiles & $\begin{array}{l}\text { Sewers, Sewing machinists, } \\
\text { Dress makers }\end{array}$ & 0.940 & 0.553 & 0.623 \\
\hline 4 LAUNDRY & Laundry & $\begin{array}{l}\text { Launderers, dry cleaners and } \\
\text { pressers, Pressers, textile, } \\
\text { garment, and related materials }\end{array}$ & 0.760 & 0.889 & 0.662 \\
\hline \multirow[t]{2}{*}{$\begin{array}{l}5 \text { GARDENING AND PET } \\
\text { CARE }\end{array}$} & Gardening & $\begin{array}{l}\text { Landscaping and } \\
\text { groundskeeping workers, Fishing } \\
\text { and other elementary agriculture } \\
\text { occupations n.e.c., Gardeners } \\
\text { and landscape gardeners }\end{array}$ & 0.760 & 0.362 & 0.486 \\
\hline & Pet care & $\begin{array}{l}\text { Animal trainers, Nonfarm animal } \\
\text { caretakers, Animal care services } \\
\text { occupations n.e.c., Veterinary } \\
\text { nurses, Pet groomers, Pet shop } \\
\text { staffs }\end{array}$ & 0.593 & 0.108 & 0.525 \\
\hline 6 SHOPPING & Shopping & Janitors and cleaners, Maids & 0.660 & 0.827 & 0.681 \\
\hline 7 OTHER HOUSEWORK & Home maintenance & $\begin{array}{l}\text { Carpenters, Plumbers, pipefitters } \\
\text { and steamfitters, Furniture } \\
\text { finishers, Janitors and cleaners }\end{array}$ & 0.650 & 0.663 & 0.567 \\
\hline
\end{tabular}


Car maintenance

Service use

Household management

Other housework

8 CHILD CARE
Electronic equipment installers and repairers, motor vehicles,

Vehicle technicians, mechanics

$0.610 \quad 0.868$

0.559

and electricians

Janitors and cleaners, Maids

Janitors and cleaners, Maids

Janitors and cleaners, Maids

Childcare workers, Childminders and related occupations

Childcare workers, Childminders and related occupations

Childcare workers, Childminders and related occupations

Childcare workers, Childminders and related occupations

Taxi and cab drivers and

chauffeurs, Janitors and cleaners,

Maids

$\begin{array}{lll}0.660 & 0.827 & 0.681\end{array}$

$\begin{array}{lll}0.660 & 0.827 & 0.681\end{array}$

$\begin{array}{lll}0.660 & 0.827 & 0.681\end{array}$

$\begin{array}{lll}0.084 & 0.003 & 0.558\end{array}$

$\begin{array}{lll}0.084 & 0.003 & 0.558\end{array}$

$\begin{array}{lll}0.084 & 0.003 & 0.558\end{array}$

$\begin{array}{lll}0.084 & 0.003 & 0.558\end{array}$

Escorting a child

Medical assistants, Personal care aides, Care workers and home carers, Home helpers, Medical 


\subsection{Matching paid work occupations to unpaid work tasks}

To predict time use on these activities after automation, we linked our 19 activities with relevant paid work occupations (see Table 2). The matching method in linking each unpaid work activity with paid work occupations follows the replacement cost method specialist approach (RC-S) that is commonly used in valuating unpaid work to relate it to the System of National Accounts (SNA) (UNECE, 2017). The RC-S method links each unpaid work activity with paid work occupations of the specialists who are doing similar work and applying their market wage rates to the hours spent on each unpaid work activity. We mostly follow the RC-S method as applied by the Economic and Social Research Institute (ESRI) of the Government of Japan's cabinet office in 2018 (ESRI 2018). ${ }^{4}$ Having linked each unpaid work activity with relevant paid occupations, we assign the automation scores of those paid occupations to the 19 unpaid work activities. In cases where more than one occupation is assigned to an unpaid work activity, we use the mean value of the assigned automation scores.

In linking the automation scores with unpaid work activities, we used three different sets of automation scores. The first set of scores is taken from Frey and Osborne (2013). It is based on US occupational data and indicates the predicted probability of full automation for each occupation. To create this measure, Frey and Osborne first selected 70 occupations from the US O-NET database ${ }^{5}$, an online database of US occupations with detailed job characteristics. They asked machine learning experts to judge whether these selected 70 occupations could be fully automated, based on the occupations' task composition and skill requirements as described in the O-NET database. In the next step, using 35 hand-labelled occupations as training data, 35 occupations as testing data, and occupation characteristics available in the O-NET database as parameters, Frey and Osborne fit three different models and compare their ability to reproduce the human expert predictions. They then applied the best performing model, a Gaussian process classifier, to estimate the probability of full automation of the remaining other 632 occupations in the US O-NET database based on their characteristics. We refer to the predicted probabilities obtained for the whole list of the 702 US occupations as the Frey and Osborne automation score or $\mathrm{F} \& \mathrm{O}$ automation score.

The second set of automation scores comes from a study that applied Frey and Osborne's methodology to data on occupational characteristics in Japan (Frey, Osborne, and Nomura Research Institute, 2015). The study uses the job description database for 601 Japanese occupations compiled by the Japan Institute for Labour Policy and Training (JILPT), a research institute under the supervision of the Ministry of Health, Labour and Welfare. Like the O-NET database in the US, JILPT's database provides a detailed description of job characteristics for each of the 601 Japanese occupations in the database. The study follows the methodology from the Frey and Osborne (2013) research. In our paper we refer to the predicted probabilities of full automation calculated by (Frey, Osborne, and Nomura Research Institute, 2015) as the NRI

\footnotetext{
${ }^{4}$ We do not follow the ESRI approach in the following cases: 1. gardening is included in the food management category in ESRI's report using STULA 2016 (ESRI 2018) and pet care is not included into the definition of unpaid work at all. We kept "gardening and pet care" as an independent category and assigned relevant specialist occupations for each activity ourselves. 2. ESRI's report includes physical care for non-dependent family members into "other housework". In UKTUS data it is not possible to distinguish whether a household member receiving physical help is dependent on the person providing help or not. Therefore, we merge physical care for an adult family member into one "family care" category.

${ }^{5}$ https://www.onetonline.org
} 
automation score.

The third set of automation scores is from a study that applied a task-based, rather than an occupation-based approach using occupational data from England. Using the OECD's Survey of Adults Skills (PIAAC), ${ }^{6}$ which contains a comprehensive list of tasks that people perform at their workplace, Arntz, Gregory, and Zierahn (2016) disaggregate the F\&O automation scores into single task scores and reconstruct the occupation-based automation score across 21 OECD countries based on the task compositions within and across occupations in each country. ${ }^{7}$ The UK Office of National Statistics (ONS) subsequently produced a set of automation scores for occupations in England in 2011, 2014 and 2017 using this approach (White, Lacey, \& ArdanazBadia, 2019). In this study, we use the latter set of automation scores covering 369 occupations in England in 2017 as our third set of automation scores. We refer to it the ONS automation score. While the F\&O and NRI scores are both probabilities of full automation, the ONS score indicates what proportion of each occupation is predicted to be automatable.

\subsection{Estimating changes in time use and labour supply}

Once automation scores are assigned to unpaid work activities, we estimate the impacts of different degrees of automation on (1) people's time use and (2) the amount of labour supplied to the paid labour market.

\subsubsection{Analytical sample}

In our calculations, we limit our analytical sample to adults aged 20-59 in both countries to estimate the potential impact of unpaid work automation on employment. We use time diary information collected during weekdays as we assume that only unpaid work hours during the weekdays would affect labour supply. ${ }^{8}$ As a result, our analysis is based on a total sample of 7,147 individuals from both the UKTUS 2015 and STULA 2016 surveys. The sample contains a total of 3,689 diary days provided by 2,464 individuals in Japan and 4,697 diary days provided by 4,683 individuals in the UK (Table 2). We use original survey weights from UKTUS and STULA to correct for both the survey designs.

Table 2. Number of diary days (individuals in brackets)

\begin{tabular}{lrrrr}
\hline & \multicolumn{2}{c}{ Japan } & \multicolumn{2}{c}{ UK } \\
& Men & Women & \multicolumn{1}{c}{ Men } & \multicolumn{1}{c}{ Women } \\
\hline $20-29$ & 294 & 253 & 445 & 551 \\
& $(196)$ & $(177)$ & $(443)$ & $(550)$ \\
$30-39$ & 398 & 439 & 521 & 623 \\
& $(267)$ & $(290)$ & $(521)$ & $(621)$ \\
$40-49$ & 567 & 629 & 571 & 751 \\
& $(376)$ & $(411)$ & $(568)$ & $(749)$ \\
$50-59$ & 550 & 559 & 600 & 635
\end{tabular}

\footnotetext{
${ }^{6}$ https://www.oecd.org/skills/piaac/

${ }^{7}$ A regression model is used to disaggregate F\&O's occupation-level automation scores into the single-task basis. In the model, the individual worker characteristics and the task compositions of individuals' occupations are used as the explanatory variables and regressed on F\&O's occupation-level automation scores. The US data is used to estimate the model and the estimated parameters are applied to other OECD country data to reconstruct the occupation-level automation scores in each country (Arntz, Gregory and Zierahn 2016).

${ }^{8}$ To check robustness of our estimates we replicated our analysis including time diaries collected during weekend days when respondents reported working on a given weekend. The results are very similar.
} 


\begin{tabular}{rrrrr} 
& $(365)$ & $(382)$ & $(598)$ & $(633)$ \\
\hline Total & 1809 & 1880 & 2137 & 2560 \\
& $(1204)$ & $(1260)$ & $(2130)$ & $(2553)$ \\
\hline
\end{tabular}

\title{
3.3.2 Estimating Time Use on Unpaid Work After the Automation
}

We calculate individuals' time spent on each of our 19 domestic work activities assuming that these activities are automated to the full possible extent as predicted in F\&O, NRI and ONS scores.

\author{
Time Use $e_{s, j, i}=$ Time Use $_{j, i} *(1-$ Automation Score $)$ \\ $s:$ Type of Automation Score, $j:$ Type of Unpaid Work Activity, $i:$ Individual $i$
}

To estimate time use after the automation, we simply multiply (1 - Automation Score) with respondents' actual time use in each unpaid work activity. For example, if the automation score of a certain activity is 0.6 , we assume that automation will result in a $60 \%$ reduction in time used on this activity. The estimated time use on this activity will thus be $40 \%$ of each respondent's current actual time use.

We are aware that the F\&O and the NRI automation scores indicate probabilities of full automation at the occupation level, rather than the proportion of the job expected to be automated. The ONS score, in contrast, estimates the proportion of tasks in a given occupation that is expected to be automated in the near future. Over a substantial number of activities in which no individual activity dominates, however, the expected probability of automation and the expected share of automated time converge. Based on this intuition we will interpret all the three automation scores as proportion of the job expected to be automated. This approach enables us to examine the potential impacts of automation in unpaid work using both occupation and taskbased automation estimates. The list of unpaid work activities as well as linked occupations and assigned automation scores are documented in Table 1.

\subsubsection{Estimating Potential Labour Supply After the Automation of Unpaid Work}

Once we have calculated time use for each time diary record, we estimate the potential impact of domestic work automation on the labour supply in Japan and the UK. Our definition of the "potential labour force" is men and women aged 20-59 who are neither in education nor in the labour market and spend time on unpaid work during core working hours (from 8 am to $8 \mathrm{pm}$ ) during weekdays. We define individuals as potential full-time workers if they are estimated to have more than 8 hours of free time during the core working hours once some of the unpaid work they are currently engaged in is automated. We define individuals as potential part-time workers if time freed up through automation is less than 8 hours but more than 4 hours. Both UKTUS and STULA time-diary surveys make it possible to identify how many hours (if any) of unpaid work activities are carried out during the core working hours for each time diary day. ${ }^{9}$

\footnotetext{
${ }^{9}$ When automation scores are applied to each unpaid work activity, we assume that individuals will prioritise freeing
} 
Potential full-time workers and potential part-time workers are mutually exclusive so that no individual is simultaneously identified as belonging to both categories.

Our estimated measure of potential full-time/part-time workers overestimates the labour supply increase for at least two reasons. First, people are out of the labour force for many reasons other than doing unpaid work. Therefore, just reducing unpaid work may not directly motivate these people to take up full-time or part-time jobs. Second, automation scores used in this study are from those of paid occupations, and they may be high-end estimates of domestic work automatability. As indicated above, households generally have fewer opportunities to benefit from economies of scale compared to businesses enterprises. Thus, our estimates can be understood as an upper bound on the number of full-time/part-time workers that could be created via the automation of unpaid work.

\section{Results}

\subsection{Susceptibility of unpaid domestic tasks to automation}

Our first research question asks how susceptible different domestic tasks are to automation. We find that most domestic work activities obtain automation scores of more than $50 \%$ based on all three underlying estimates of automation likelihood for paid work. The interpretation is that the probability of these tasks being automated is more than $50 \%$, or alternatively, that more than $50 \%$ of the time spent on these tasks could be reduced with the help of new technologies. The scores for each activity, together with the average time spent on the activity, are depicted in Figures 1-1, 1-2, and 1-3. ${ }^{10}$

The three scores result in different automation expectations of specific tasks. The ONS score places all unpaid work activities within a narrow range of $50-70 \%$, which means that 50 $70 \%$ of time used on unpaid work will be freed up after automation. Both the F\&O and the NRI scores have more variation in the distributions of unpaid work hours. In both scores, childcare has a low chance of automation ( $0-15 \%$ or $15-30 \%)$. In the NRI scores, family care and gardening/pet care also have a very low probability of automation. F\&O and the NRI scores anticipate very high automation probabilities for a few activities: According to F\&O scores, 70$85 \%$ of food management (cooking and washing dishes) and laundry (including ironing and folding) could be automated. The NRI scores are the most optimistic about future domestic automation, indicating that shopping and other housework have a high chance of automation (70-85\%) while household upkeep and laundry have the highest chance of automation (85$100 \%)$.

up their time in the following order: first in the time segment of 12:00-16:00, then in the segment of 8:00-12:00, and finally in the segment of 16:00-20:00 until the estimated day-total automation time finishes. In this way, we maximize the chance of each respondent having "free time" from unpaid work during the "core working hours" between 8 am to $8 \mathrm{pm}$.

${ }^{10}$ Note that some unpaid work activities, e.g., childcare, have different automation scores across countries. This is because the automation scores are initially assigned to 19 detailed activities. Using average scores from these specific activities we create automation scores for 9 broader activities (see Table 1 for the conversion list). 
Figure 1-1. Weekday time use on unpaid work activities across F\&O automation scores, by country
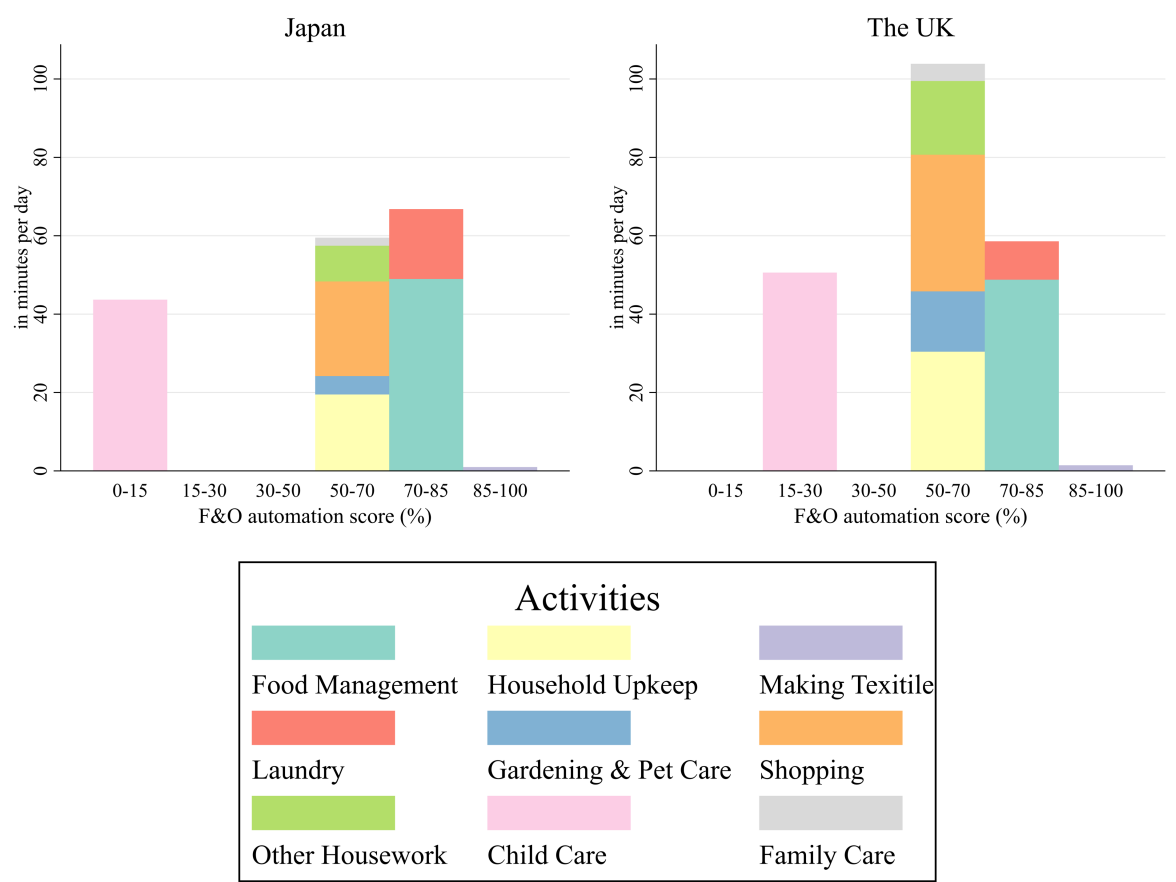

Note: Estimates based on a sample of adults aged 20-59.

Figure 1-2. Weekday time use on unpaid work activities across NRI automation scores, by country
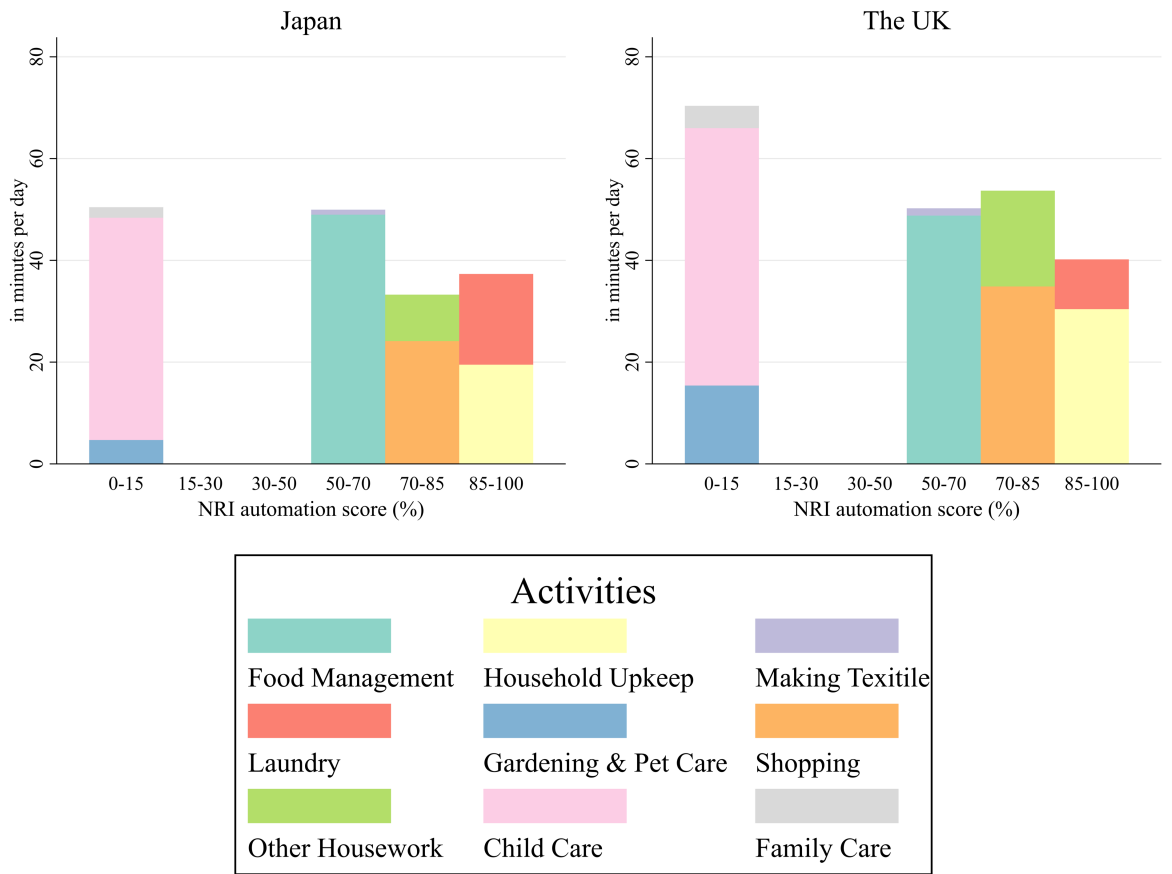

Note: Estimates based on a sample of adults aged 20-59. 
Figure 1-3. Weekday time use on unpaid work activities across ONS automation scores, by country
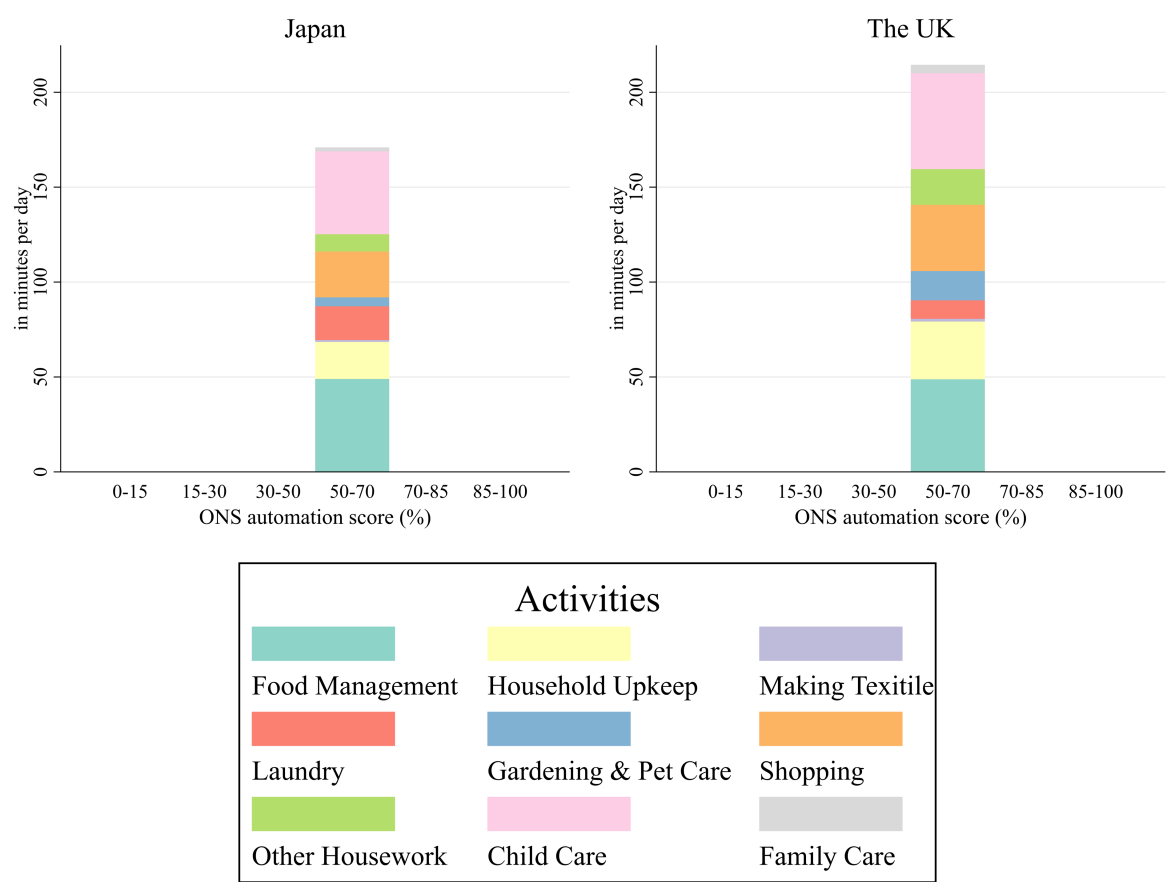

Note: Estimates based on a sample of adults aged 20-59.

\subsection{Gender differences and time savings from domestic automation}

Our second research question asks how much time would be freed up for men and women in Japan and the UK if domestic work tasks were automated to their full predicted potential. To examine this, we calculate the annual population-aggregated time use figures for each unpaid work activity by gender and distribute them across our automation scores. ${ }^{11}$ An average Japanese man aged 20-59 spends 56 minutes on unpaid work on an average weekday, while an average Japanese woman spends 292 minutes. In the scenario based on F\&O automation scores, all unpaid work apart from childcare is highly automatable. In Japan, men spend $70 \%$ of their unpaid weekday work time on activities other than childcare and women spend $75 \%$ of their unpaid work time on such activities (Figure 2-1). An average working age man in the UK spends 141 minutes on unpaid work on weekdays. Eighty two percent of this time is spent on nonchildcare tasks that are highly automatable. Finally, an average UK woman aged 20-59 spends 290 minutes on unpaid work on an average weekday and $74 \%$ of this time is spent in activities with high likelihood of automation (Figure 2-2).

\footnotetext{
${ }^{11}$ In this paper we show the results only for $\mathrm{F} \& \mathrm{O}$ automation scores. Gender differences are similarly large with NRI and ONS automation scores available upon request.
} 
Figure 2-1. Weekday time use on unpaid work across Frey \& Osborne (F\&O) automation scores in Japan by gender
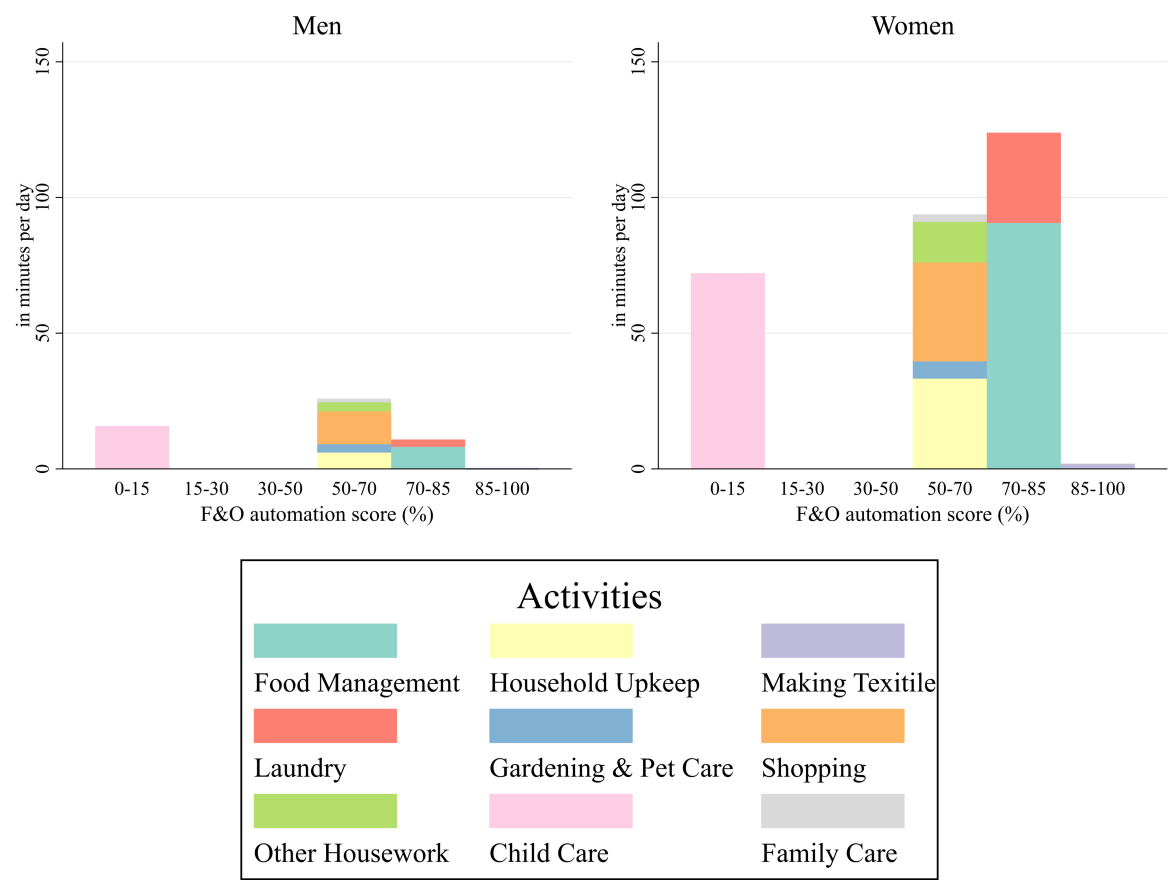

Note: Estimates based on a sample of adults aged 20-59.

Figure 2-2. Weekday time use on unpaid work across Frey \& Osborne (F\&O) automation scores in the UK by gender
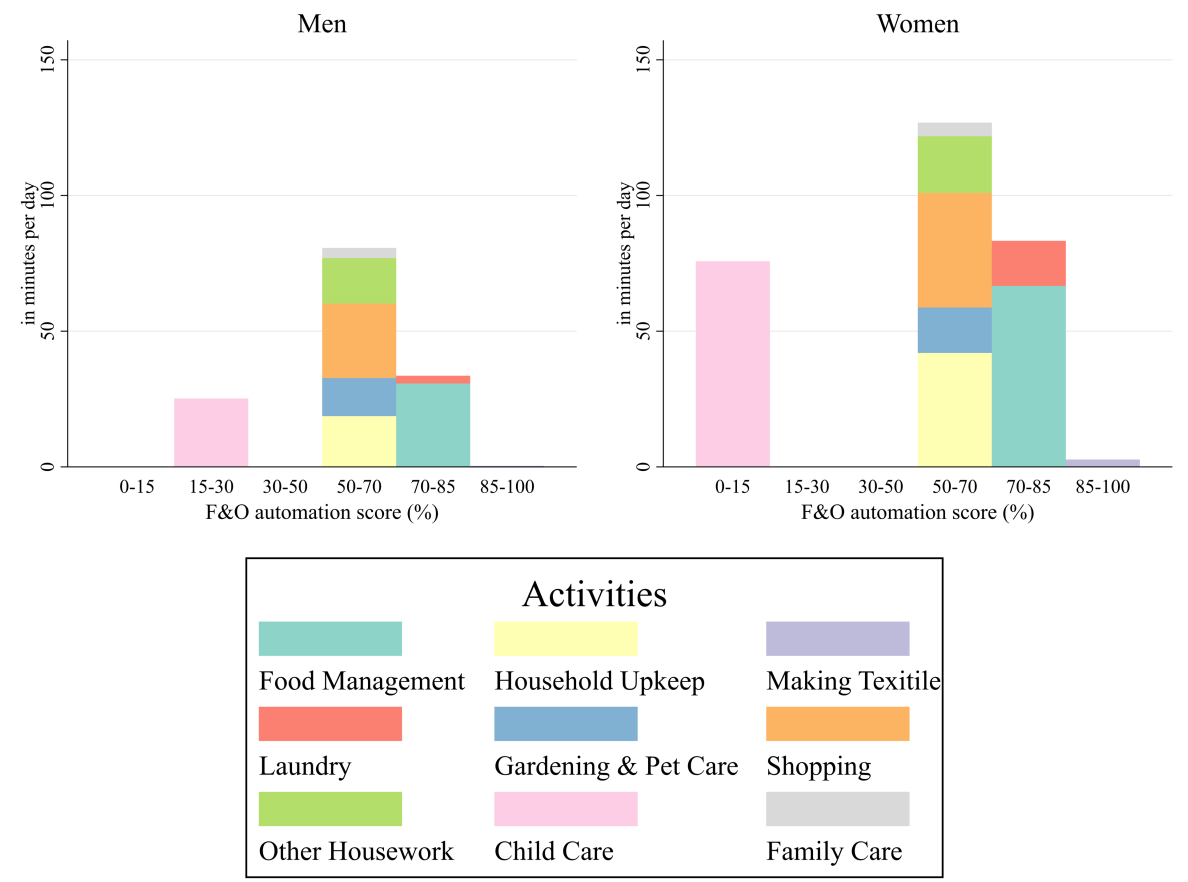

Note: Estimates based on a sample of adults aged 20-59.

Table 3 shows how these differences add up over a year. UK men spend more than twice as much time on unpaid work as Japanese men do. UK women spend almost twice as much time 
on unpaid work as UK men do, and Japanese women spend more than four times as long on unpaid work as Japanese men. The difference in women's unpaid work is small between the two countries.

Table 3. Annual hours spent on unpaid work by men and women aged 20-59

\begin{tabular}{lllll}
\hline & Men & \multicolumn{3}{c}{ Women } \\
& Japan & UK & Japan & UK \\
\hline $\begin{array}{l}\text { Yearly unpaid work } \\
\text { hours }\end{array}$ & 445 & 947 & 1818 & 1793 \\
\hline
\end{tabular}

Note: these hours are calculated from weekdays and weekends data.

The graphs highlight that the potential impact of automation on unpaid work would be very high for women, particularly in Japan.

In the next step we calculate how much domestic work time could be saved if the technology was applied as predicted. The results are shown in Figure 3. Compared with the observed total time use on unpaid work, automation is expected to reduce time use on unpaid work by $50-60 \%$ in both countries for both genders. Despite the differences in the distributions of unpaid work time across the three automation scores, the estimated potential impacts of automation on time use are very similar across the three scores. While at the activity level there are substantive differences across the three scores, this variation is largely cancelled out once activities are aggregated.

Figure 3. Observed and estimated time use on unpaid work in Japan and the UK by gender

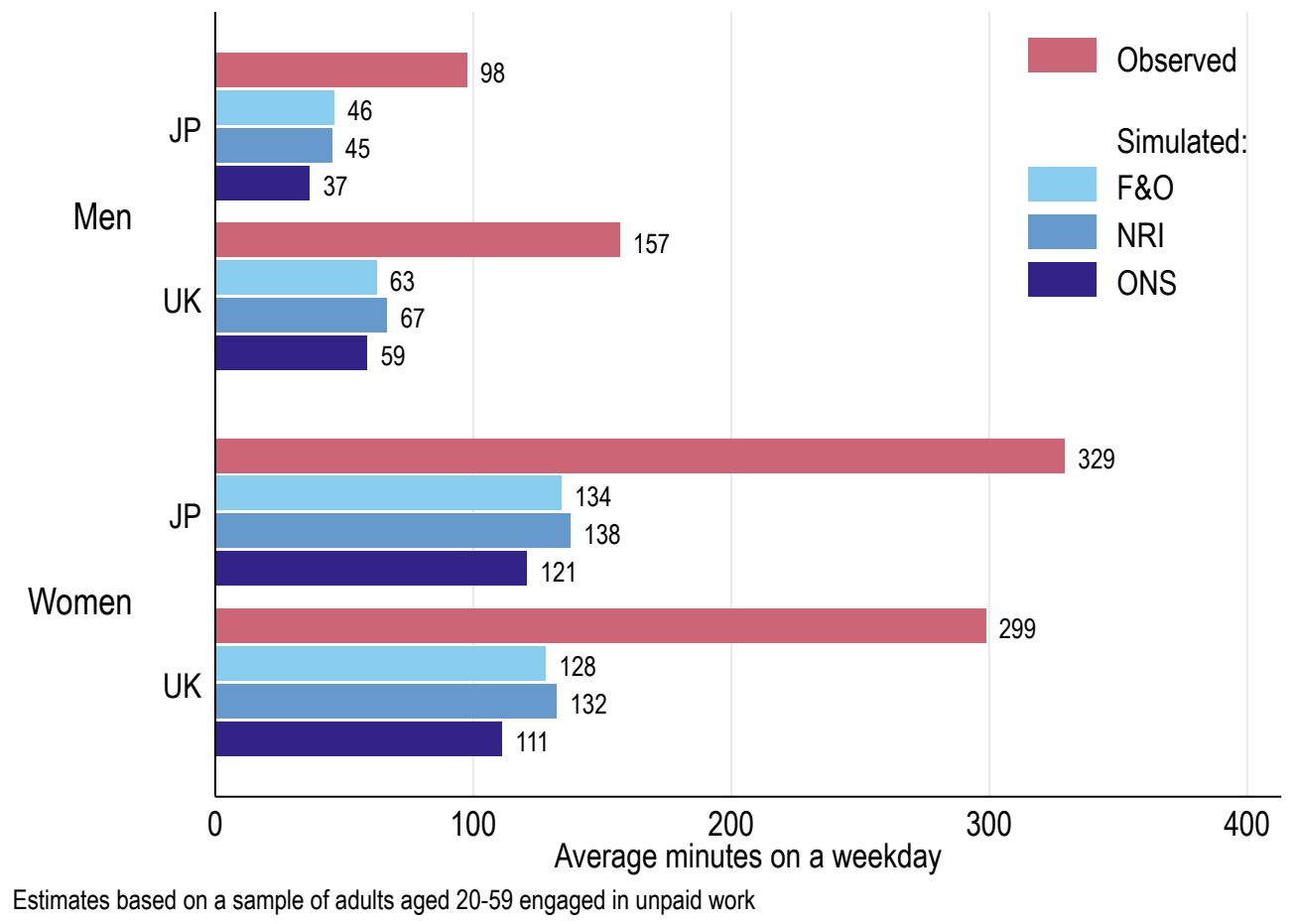

As women do the majority of domestic work in both countries (80\% for Japan and $65 \%$ for the UK), the potential impact of unpaid work automation is especially high for women, particularly in Japan, where automation could reduce women's average domestic work time from 5.5 hours to just over two hours on an average weekday, freeing up 3.5 hours of time. A 
Japanese man would save just under an hour on an average weekday, a UK man - an hour and a half, and a UK woman around 3 hours (Figure 3). This would liberate considerable time for welfare-enhancing activities like sleep, leisure, skills acquisition, or paid work - the focus of the next section.

\subsection{Potential impacts on labour supply}

Our third research question asks how the estimated potential changes in time use could impact the supply of workers to the paid labour market. Figure 4-1 shows the estimated change in the number of potential full-time workers in Japan and the UK by gender as a percentage of the total number of working-age men and women respectively. As expected, the number of potential new full-time workers is the highest among Japanese women, amounting to around $2 \%$ of workingage women (or 615,920 possible new female full-time workers) and lowest among Japanese men at around $0.3 \%$ of working-age men. The same figures for UK women and men are around $0.5 \%$ (or 173,605 possible new female full-time workers) and 1\%, respectively.

Time use data reveals that UK women's unpaid work time is concentrated in the core work hours (between 8 am and $8 \mathrm{pm}$ ), while Japanese women's domestic work is more evenly distributed throughout the day. As a result, even if substantial automation takes place, few UK women would secure eight consecutive hours free from unpaid work during core working hours unless domestic work is further reorganised. UK men tend to have a similar time use pattern to that of UK women, but they spend less time on unpaid work. Their labour market participation rate is also not as high as that of Japanese men. As a result, UK men have the second largest share of potential new full-time workers in the sub-populations examined. Finally, Japanese men have the lowest potential for additional full-time workers after some unpaid work is automated. This is because the employment rate for Japanese men aged 20-59 already is very high (83.8\%). Moreover, about half of the Japanese men in this age group who do not have paid work do not spend any time on unpaid work on weekdays. Therefore, their labour supply is not sensitive to time-saving domestic technology. 
Figure 4-1. Change in potential full-time workers in Japan and the UK by gender

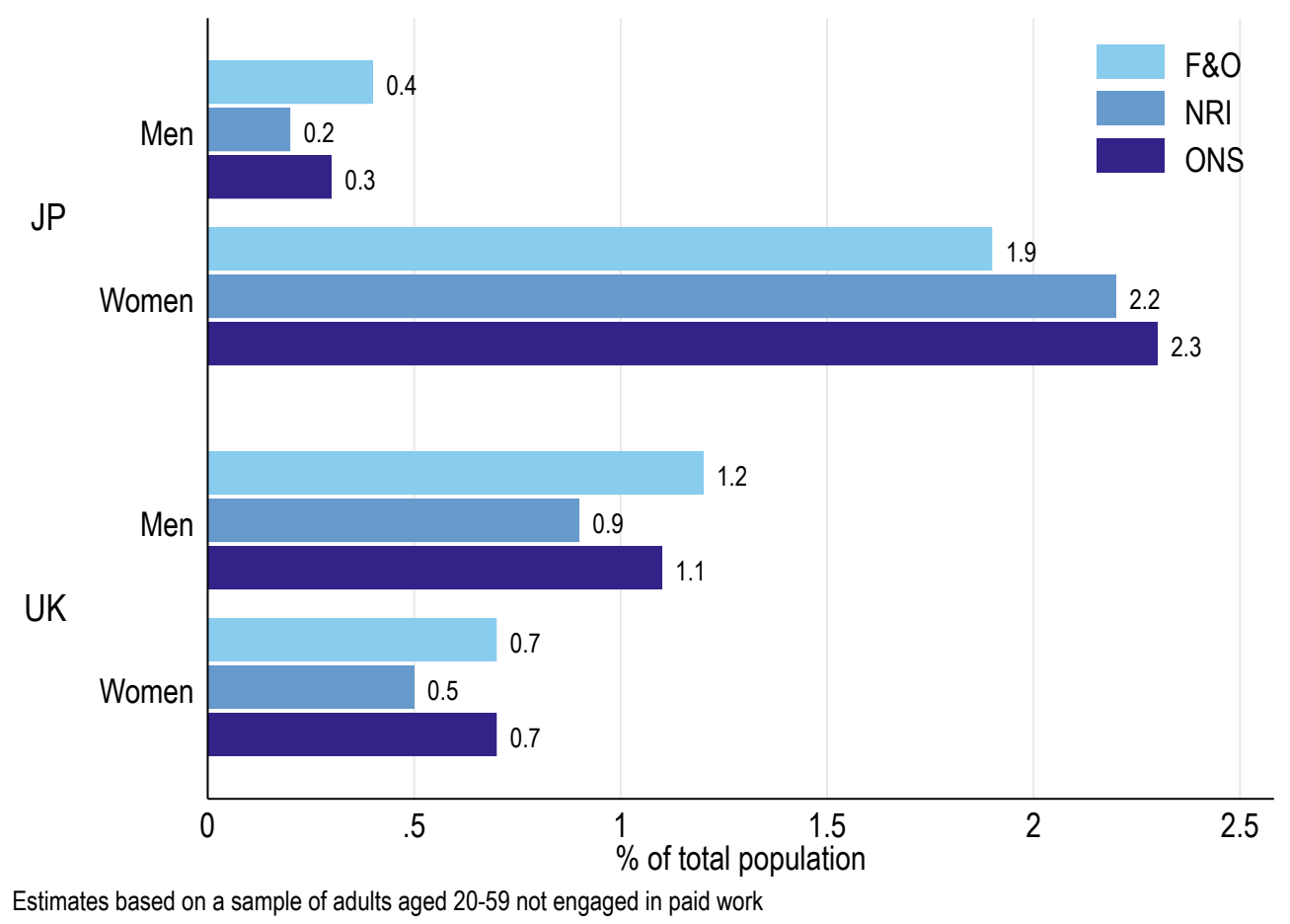

As people engage with different types of unpaid work activities in different stages of life, the impact of automation on the unpaid workload differs by age as well as gender. Here, we examine how the impacts of unpaid work automation differ by age in women, given their greater unpaid workload. Figure 4-2 shows the percentages of potential new full-time workers among women by 10-year age groups in Japan and the UK. In Japan the proportion of new full-time workers among women is similar across all age groups apart from women in their 30s. The low potential for additional full-time employment among Japanese women in their 30s probably results from the fact that these women are most likely to have young children who impose care requirements throughout the day that cannot be sufficiently alleviated with technology. In the UK, the estimated percentage of potential female full-time workers is high only for women in their 20s; presumably, most women in this group have not yet had children. Very few UK women in their 30s and older who are currently not working will have enough time free from unpaid work to work full-time even if a substantial amount of the unpaid work they do is automated. 
Figure 4-2. Percentage of potential female full-time workers in Japan and the UK by age, population age $20-59$
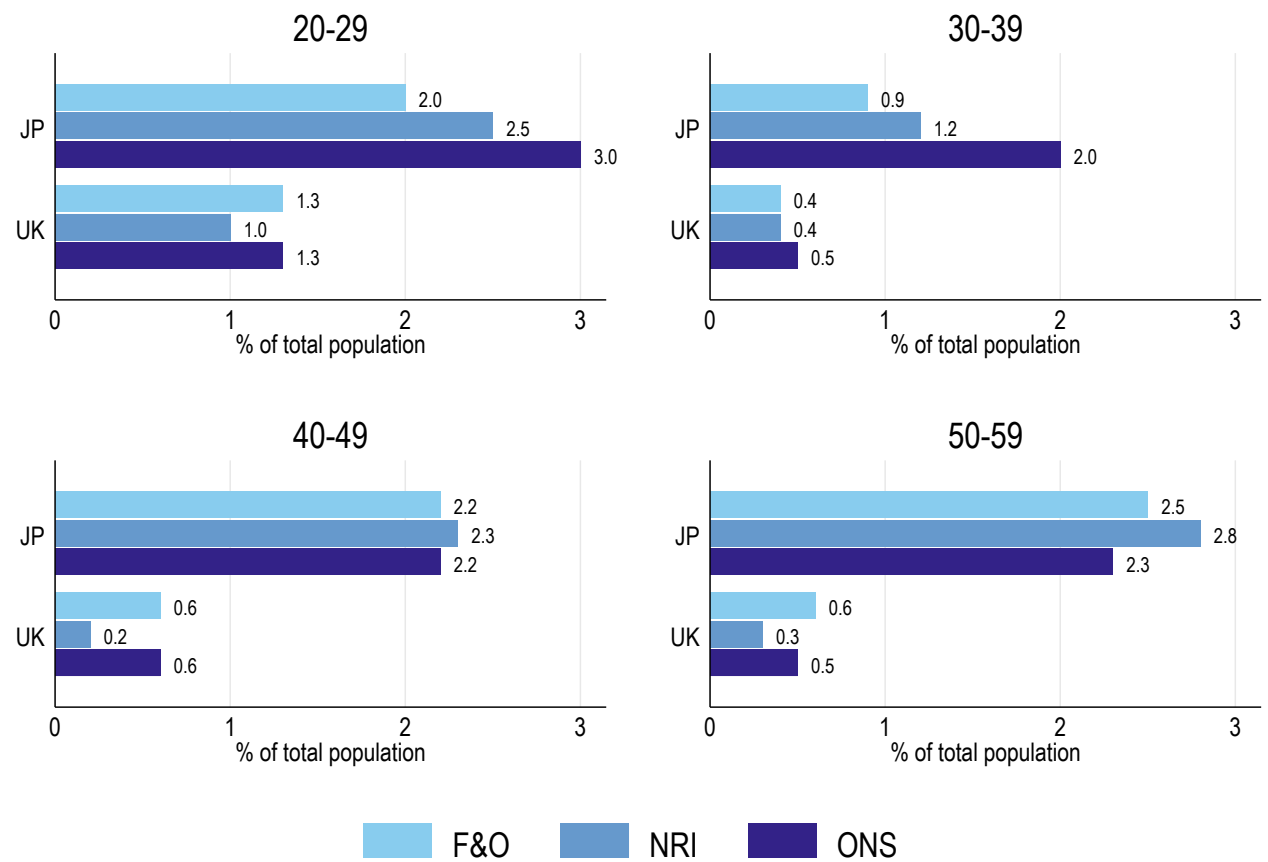

Estimates based on a sample of women aged 20-59 not engaged in paid work

Finally, we show the estimated number of potential workers who could take on part-time jobs after some of the unpaid work they do is automated. As expected, the percentages of potential new part-time workers are much higher than those of full-time workers. Figure 5-1 shows that the shares of potential new part-time workers among those aged 20 to 59 are the highest among Japanese women at around 5-7\%. The second highest group for this category of workers is UK women at around 4\%, followed by UK men at around $2 \%$. Japanese men have the lowest potential for new part-time workers at 1\%. Considerably fewer UK women than men do not engage in paid work on weekdays (54.2\% vs $69.4 \%$ in our UKTUS sample).

Consequently, we find many more potential part-time workers among UK women, than among UK men. ONS scores result in higher estimates of potential new part-time workers compared to the other two scores. 
Figure 5-1. Percentage of potential part-time workers in Japan and the UK by gender

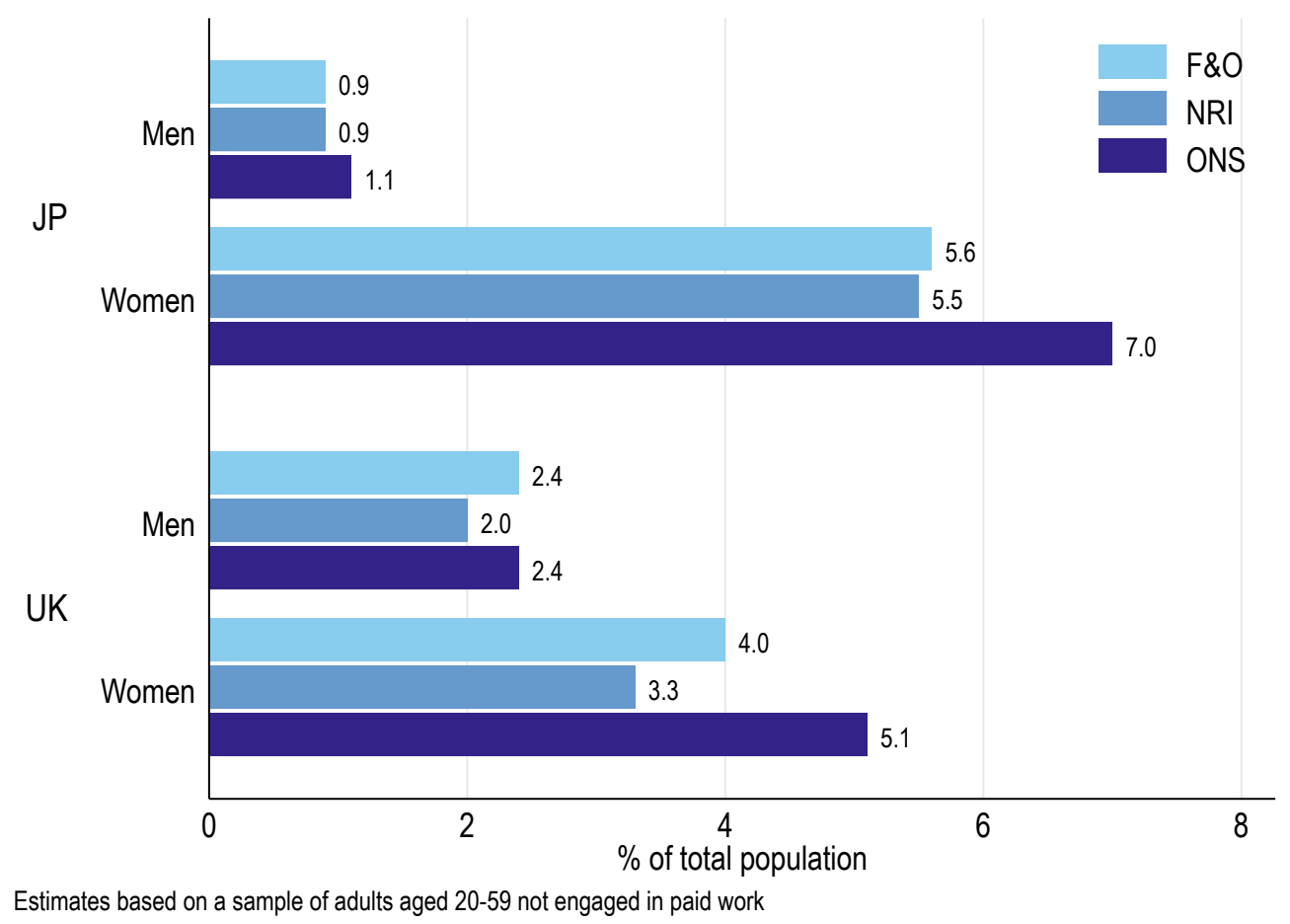

Figure 5-2 shows the estimated percentages of potential new female part-time workers by age in Japan and the UK respectively. The percentage of potential female part-time workers is higher among those in their 40s and older in Japan at around 6-9\%. The percentages calculated with the F\&O and the NRI scores are relatively low for those in their 20 s and the 30 s $(2-4 \%)$, while those calculated using the ONS scores result in substantially higher values (4-9\%). This is because the ONS score assigns a much higher automation score for childcare than the other two scores (see Table 1). In the UK, the percentage of potential new female part-time workers is the highest among those in their 50s (5-7\%), followed by those in their 30s and the 40s $(3-5 \%)$. Again, the calculated results with the ONS score are higher for younger age categories $(20 \mathrm{~s}$ and 30s) because of the higher automatability score of childcare. 
Figure 5-2. Percentage of potential female part-time workers in Japan and the UK by age

20-29
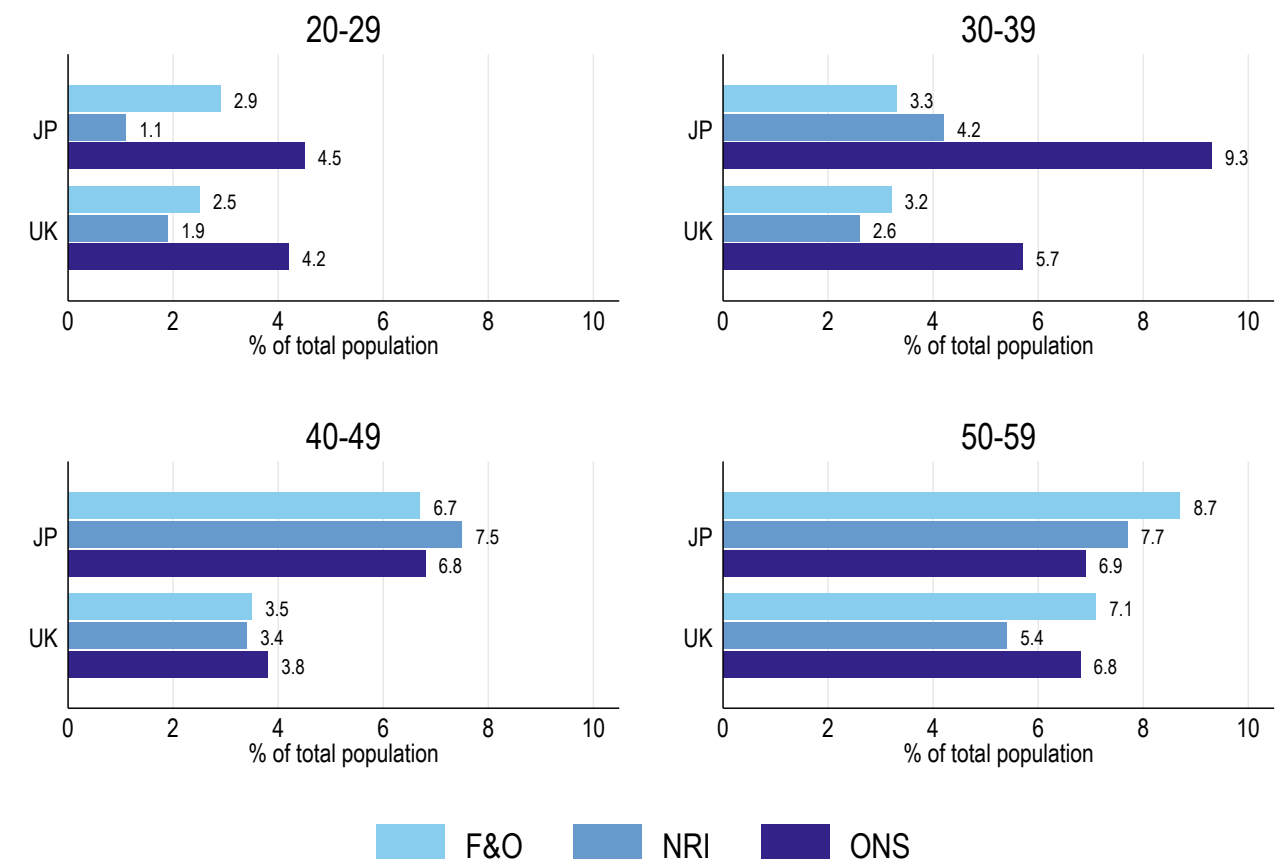

Estimates based on a sample of women aged 20-59 not engaged in paid work

\section{Discussion and conclusions}

The future of work has attracted much academic and policy attention in recent years (Autor et al., 2003; Goos and Manning, 2007; Autor and Dorn, 2013; Frey and Osborne 2017). Unpaid household and care work is as important as paid work for wellbeing and the economy, as has been amply demonstrated during the COVID-19 pandemic. Yet the future of unpaid work has been neglected in this literature. In this article, we addressed this issue by estimating for the first time the potential impacts of new technologies on unpaid work in the UK and Japan, two highly developed countries where time use patterns in domestic work differ substantially. We applied three sets of automation scores that Frey and Osborne (2017) and other researchers developed for paid work occupations to similar domestic work tasks. This enabled us to estimate the rough probabilities of automation for various types of domestic work. We estimated future time use patterns by applying these automation probabilities to existing time use data. Our calculations offered the first estimates of how automation of household production using the latest wave of "smart" and "AI" technologies could change daily lives and how it could influence the labour supply in both countries.

We found that unpaid work, and housework in particular, is highly susceptible to automation across all the three automation score sets used. Automation could reduce total time used on unpaid work by 50-60\% in both Japan and the UK, amounting to a reduction in the domestic workload by around three hours per day for women in these countries. At the upper boundary, we estimate that time savings through domestic technology could allow Japanese women in prime working age to increase their labour market participation rate from $72.8 \%$ to $80.8 \%$, a level similar to that of egalitarian Nordic countries. Estimated employment increases are less dramatic for women in the UK and for men in both countries. The stronger potential impact on gender equality in Japan is to some extent at least due to the higher current levels of 
gender inequality there.

The future of work literature has focused on the idea that firms can substitute new technologies for various types of labour (Arntz, Gregory, \& Zierahn, 2017; Autor \& Dorn, 2013; Frey \& Osborne, 2017; Stephany \& Lorenz, 2021). New technologies can thus address labour shortages but also bring about at least temporary unemployment as workers are displaced by robots. Our study points to the possibility that new technologies could have similar effects on labour markets also via a second, indirect channel: the reduction of time spent on unpaid work in the domestic sphere. By reducing the time spent on unpaid work, new technologies can free up more labour supply and thus address labour shortages. This means that the impacts of technology on labour markets is more complex than suggested by estimates that only consider paid work.

Automation of unpaid work could also partially compensate for future labour shortages expected from population decline in Japan. Automation of domestic work is an important dimension that remains underexplored in this context and that could interact with future demographic change. Not only could domestic technology increase the labour supply but ageing itself could accelerate the development and deployment of domestic technologies. These implications demonstrate the importance of including unpaid work in the picture when considering the future of work and society more broadly.

\section{Future research}

This paper offers the first estimates of the likelihood of automation of different domestic work activities. An important weakness of the estimates is that they are based on the assumption that households will adopt technologies uniformly, independently of the technologies' costs and household members' preferences. These assumptions, of course, are unrealistic.

Many "smart" and "AI" technologies that alleviate unpaid domestic work tasks are likely to carry a substantial price tag when they hit the market. As a result, they could exacerbate existing "available time" inequalities between rich and poor (e.g., ONS, 2016). Members of more affluent households could free up considerably more time to invest in their careers, human capital development and well-being compared to members of less affluent households. At the same time, more educated people may be warier of adopting technologies that will limit interactive care work (like reading to, educating, and playing with children), resulting in a new digital divide where children and dependent elderly from more affluent households will receive more human care than their counterparts from poorer backgrounds.

Gender attitudes and values as well as relative wage levels available in formal employment compared with the price of smart technologies may also be important. Domestic responsibilities are often the reason why Japanese women opt for non-standard jobs. These jobs include part-time as well as fixed-term contracts. Such jobs tend to have shorter and fixed hours and are also associated with lower pay, fewer benefits, and lower chances for promotion in Japan. Among women aged 40 to 44, for example, non-standard employees make around 30\% less compared to regular workers annually (Ministry of Health Labour and Welfare, 2021). Therefore, low-paid workers in part-time employment may continue to do household chores instead of paying for labour-saving domestic technology because they perceive a return to the labour market as less rewarding. For younger generations who have the option of using smart technologies before having children, by contrast, new technologies may help women maintain better-paid careers and preserve their human capital even as they move to having children. 
As discussed in the research design section, the use of automation scores from paid occupations may result in overestimation of unpaid work automation. Our assumption that every non-working person will join the labour market if only they had enough free time is also an oversimplification. Our estimated potential labour supply represents the upper limit on new workers, used to illustrate the scope of potential change automation could bring about. We do not consider other uses of the free time generated by domestic technology and do not consider the quality of these new workers or how they are matched in the labour market. When discussing cross-country variations in the consequences of domestic work automation, we do not account for country differences in people's willingness to adopt domestic automation technologies (e.g., Fortunati, 2018). To address these methodological shortcomings, future forecasting research should consider the affordability of domestic automation technologies and examine their social acceptability across different demographic groups.

Finally, this study does not address the question of whether everything that can be automated should be automated. Automation raises issues around topics such as data privacy, quality of care, and consequences to human relationships. Similarly, we are silent on how household production standards could change when automation is adopted. Past innovations in household automation made possible new standards in hygiene and nutrition that created new tasks. Smart technologies, too, could lead to changes in domestic work rather than merely reductions in the time spent on it. These are important topics that need to be addressed in future research.

\section{Acknowledgements}

This research was supported by a UK-Japan collaborative grant jointly awarded by UK Research and Innovation (grant number ES/T007265/1; PI Ekaterina Hertog) and by the Research Institute of Science and Technology for Society (RISTEX) of the Japan Science and Technology Agency (grant number JPMJRX19H4; PI Nobuko Nagase). This project also benefited from funding from the European Union's Horizon 2020 research and innovation programme under the European Research Council Consolidator Grant agreement No 771736.

\section{Declarations of interest: none}

\section{References}

Ahuja, K., Chandra, V., Lord, V., \& Peens, C. (2021). Ordering in: The rapid evolution of food delivery. Retrieved from https://www.mckinsey.com/industries/technology-media-andtelecommunications/our-insights/ordering-in-the-rapid-evolution-of-food-delivery

Arntz, M., Gregory, T., \& Zierahn, U. (2016). The Risk of Automation for Jobs in OECD Countries: A Comparative Analysis. OECD Social, Employment and Migration Working Papers. Article. OECD Publishing, Paris. Retrieved from dx.doi.org/10.1787/5jlz9h56dvq7-en

Autor, D., Dorn, D., 2013. The growth of low skill service jobs and the polarization of the US labor market, Am. Econ. Rev. 103 (5). 1553-1597.

Autor, D., Levy, F., Murnane, R.J., 2003. The skill content of recent technological change: an 
empirical exploration. Q. J. Econ. 118 (4), 1279-1333.

Baarsma, B., \& Groenewegen, J. (2021). COVID-19 and the Demand for Online Grocery Shopping: Empirical Evidence from the Netherlands. De Economist, 169(4), 407-421. doi:10.1007/s10645-021-09389-y

Bowden, S., \& Offer, A. (1994). Household Appliances and the Use of Time: The United States and Britain Since the 1920s. The Economic History Review, 47(4), 725-748. doi:10.2307/2597714

Broussard, M. (2018). Artificial unintelligence: how computers misunderstand the world. Cambridge, Massachusetts: The MIT Press.

Cavalcanti, T. V. D., \& Tavares, J. (2008). Assessing the "engines of liberation": Home appliances and female labor force participation. Review of Economics and Statistics, 90(1), 81-88. Retrieved from < Go to ISI >://WOS:000255789500007

Cowan, R. S. (2012). The "Industrial Revolution" in the Home: Household Technology and Social Change in the 20th Century. In F. C. Nancy (Ed.), Volume 4/2 Domestic Ideology and Domestic Work (pp. 375-397): K. G. Saur.

ESRI (Economic and Social Research Institute). (2018). Monetary Valuation of Unpaid Work in 2016 -Japan- (in Japanese), Retrieved from https://www.esri.cao.go.jp/jp/sna/sonota/satellite/roudou/contents/pdf/190617_kajik atsudoutou.pdf

Frey, C., \& Osborne, M. (2013). 'The Future of Employment: How Susceptible Are Jobs to Computerisation?' Retrieved from https://www.oxfordmartin.ox.ac.uk/downloads/academic/The_Future_of_Employmen t.pdf

Frey, C., \& Osborne, M. (2017). 'The Future of Employment: How Susceptible Are Jobs to Computerisation?’ Technological Forecasting and Social Change 114:254-80. doi:https://doi.org/10.1016/j.techfore.2016.08.019

Frey, C. B., Osborne, M. and Nomura Research Institute. (2015). Computerization and the Future of Work in Japan, NRI report. Retrieved from https://www.nri.com//media/Corporate/jp/Files/PDF/journal/2017/05/01.pdf?la $=$ jaJP\&hash=AE4E0AC424AFE77A5F9EDC79B1BA7B9BA1C4AD9C

Fortunati, L. (2018). Robotization and the domestic sphere. New Media \& Society, 20(8), 26732690. doi:10.1177/1461444817729366

Gershuny, J. (2018). Gender Symmetry, Gender Convergence and Historical Work-time Invariance in 24 countries. Center for Time Use Research. Retrieved from https://www.timeuse.org/sites/default/files/201802/CTUR $\% 20 W \mathrm{~W} \% 202 \% 202018$ 0.pdf. IATUR slides with full list of countries http://www.ksh.hu/iatur2018/iatur40_gershuny.pdf

Gershuny, J., \& Harms, T. A. (2016). Housework Now Takes Much Less Time: 85 Years of US Rural Women's Time Use. Social Forces, 95(2), 503-524. doi:10.1093/sf/sow073

Gershuny, J., \& Sullivan, O. (2017). United Kingdom Time Use Survey, 2014-2015.

Gershuny, J., Vega-Rapun, M., \& Lamote, J. (2020). Multinational Time Use Study. . Retrieved from: http://www.timeuse.org/mtus/

Goldin, C. (2014). A Grand Gender Convergence: Its Last Chapter. American Economic Review, 104(4), 1091-1119. doi:10.1257/aer.104.4.1091

Goos, M., Manning, A., 2007. Lousy and lovely jobs: the rising polarization of work in Britain. 
Rev. Econ. Stat. 89 (1), 118-133.

Greenwood, J., Seshadri, A., \& Yorukoglu, M. (2005). Engines of Liberation. The Review of Economic Studies, 72(1), 109-133. doi:10.1111/0034-6527.00326

International Federation of Robotics. (2020). Executive Summary World Robotics 2020 Service Robots. Retrieved from

https://ifr.org/img/worldrobotics/Executive Summary WR 2020 Service Robots.pdf

Kan, M.Y.and S. Pudney. 2008. "Measurement Error in Stylized and Diary Data on Time Use."

Sociological Methodology 38:101-132.

Krenz, A., \& Strulik, H. (2022). Automation and the Fall and Rise of the Servant Economy.

Retrieved from

https://www.researchgate.net/publication/357556523_Automation_and_the_Fall_and_

Rise_of_the_Servant_Economy

Maki, A. (1996). Postwar Private Consumption Patterns of Japanese Households: The Role of Consumer Durables. PACIFIC ECONOMIC PAPERS. Retrieved from https://ideas.repec.org/p/csg/ajrcau/262.html

Ministry of Health Labour and Welfare. (2021). Basic Survey on Wage Structure 2020. Retrieved from https://www.mhlw.go.jp/toukei/itiran/roudou/chingin/kouzou/z2020/dl/06.pdf

Ollier-Malaterre, A., Jacobs, J. A., \& Rothbard, N. P. (2019). Technology, Work, and Family:

Digital Cultural Capital and Boundary Management. Annual Review of Sociology, 45(1), 425-447. doi:10.1146/annurev-soc-073018-022433

ONS. (2020). Population estimates for the UK, England and Wales, Scotland and Northern Ireland: mid-

2019. Retrieved from

https://www.ons.gov.uk/peoplepopulationandcommunity/populationandmigration/pop ulationestimates/bulletins/annualmidyearpopulationestimates/mid2019estimates

ONS. (2016). Women shoulder the responsibility of 'unpaid work'. Retrieved from

https://www.ons.gov.uk/employmentandlabourmarket/peopleinwork/earningsandwork inghours/articles/womenshouldertheresponsibilityofunpaidwork/2016-11-10

Organisation for Economic Cooperation and Development. (2020). Spending on Long-term Care, Brief Retrieved from https://www.oecd.org/health/health-systems/Spending-on-longterm-care-Brief-November-2020.pdf

Organisation for Economic Cooperation and Development. (2021). Time Use Database. Retrieved from: https://stats.oecd.org/Index.aspx?DataSetCode=TIME_USE

Pailhé, A., Solaz, A., \& Stanfors, M. (2021). The Great Convergence: Gender and Unpaid Work in Europe and the United States. Population and Development Review, 47(1), 181-217. doi:https://doi.org/10.1111/padr.12385

Reid, M. G. (1934). Economics of household production. New York: J. Wiley \& Sons.

Ruppanner, L. (2020). Motherlands: how states push mothers out of employment. Philadelphia: Temple University Press.

Singer, N. (2021). Learning Apps Have Boomed in the Pandemic. Now Comes the Real Test. The New York Times. Retrieved from https://www.nytimes.com/2021/03/17/technology/learning-apps-students.html

Statistics Bureau. (2016). Survey on Time Use and Leisure Activities. Retrieved from http://www.stat.go.jp/english/data/shakai/index.html

Statistics Bureau. (2020). Statistical Handbook of Japan 2020. Retrieved from https://www.stat.go.jp/english/data/handbook/pdf/2020all.pdf

Statistics Bureau. (various years). Survey on Time Use and Leisure Activities. . Retrieved from http://www.stat.go.jp/english/data/shakai/index.html

Stephany, F., \& Lorenz, H. (2021). The Future of Employment Revisited: How Model Selection Determines Automation Forecasts. SSRN. http://dx.doi.org/10.2139/ssrn.3835759 
UNECE. (2017). Guide on valuing unpaid household service work. Retrieved from https://unece.org/fileadmin/DAM/stats/publications/2018/ECECESSTAT20173.pdf

White, S., Lacey, A., \& Ardanaz-Badia, A. (2019). The probability of automation in England (p. 16). Office for National Statistics.

World Economic Forum. (2019). Global Gender Gap Report 2020. Retrieved from https://www.weforum.org/reports/gender-gap-2020-report-100-years-pay-equality

Yano, M. (1995). Seikatsu jikan no shakaigaku: shakai no jikan kojin no jikan (Sociology of time use: Society and time use, personal time use). Tokyo University Press. 


\section{Biographical endnote}

\section{Ekaterina Hertog}

Ekaterina Hertog is a Research Fellow at the Department of Sociology, University of Oxford. Hertog's research interests lie at the intersection of digital sociology and family sociology. She leads the UK team in the DomesticAI project that aims to scope new technologies' potential to free up time now locked into unpaid domestic labour and measure how willing people are to introduce these technologies into their private lives.

\section{Setsuya Fukuda}

Setsuya Fukuda is a social demographer working at the National Institute of Population and Social Security Research where he conducts demographic research on the inter-relationships between gender, family formation and family policy. His current research focuses on gender role division, assortative mating, fertility, and intergenerational transfers in international comparative settings, looking, in particular, at how Japan's gender structure and generational economy are changing as a consequence of population decline, new family policies and the emergence of new technologies.

\section{Rikiya Matsukura}

Rikiya Matsukura is an associate professor at the College of Economics Nihon University.

He has also been a guest researcher at the Japanese Ministry of Internal Affairs and Communications from 2002 to the present and is a consultant at the UN.

He has over 25 years of experience in demographic research, focusing on the development of statistical methods for complicated models and the application of these methodologies to socio-economic development and population change. In the field of population and economy, in recent years he has been contributing to the development of the latest economic indices, the National Transfer Accounts (NTA).

\section{Nobuko Nagase}

Nobuko Nagase is a Professor of Labour Economics and Social Policy at Ochanomizu University. She leads the Japanese team in the DomesticAI project. Her previous research explores the Japanese gender wage gap as well as the effect of labour market regulations and other institutions on work choice and family formation. Her current interest is in how technology may transform not only work but also domestic activities. She received her PhD in Economics from the University of Tokyo. She received Abe fellowship to conduct comparative female labour analysis at Harvard University and Cornell University from 2013-2015.

\section{Vili Lehdonvirta}

Vili Lehdonvirta is a Professor of Economic Sociology and Digital Social Research at the Oxford Internet Institute, University of Oxford. He is the author of Cloud Empires: How Digital Platforms Are Overtaking the State and How We Can Regain Control (MIT Press, 2022) and Virtual Economies: Design and Analysis (MIT Press, 2014). 


\section{Appendix}

\section{A.1 Time use surveys description}

The UK Time Use Survey (UKTUS) 2015 obtained a nationally representative sample of households and individuals using clustered, stratified sampling design, and asked respondents to complete time diaries for two randomly allocated days, one weekday and one weekend day (Gershuny \& Sullivan, 2017). A self-completed, open-ended, 24-hour time-diary format was used in the survey. All members of selected households aged 8 years old and older reported their main and secondary activities in 10-minute intervals. Respondents' time was coded into 277 possible activity codes. The survey was carried out over 18 months between April 2014 and December 2015.

The Japanese Survey on Time Use and Leisure Activities (STULA) 2016 is a time diary study based on a nationally representative sample selected using a two-stage stratified sampling method (Statistics Bureau, 2016). All persons aged 10 and over in the sample households were asked to respond to the survey. Survey respondents complete time diaries on 2 consecutive days. The survey was carried out over 9 days in mid-October 2016 and oversampled Fridays, Saturdays, and Sundays. The diaries reported how the individuals were spending their time in 15minute intervals. Ninety-five per cent of the respondents were administered questionnaire $A$, and five per cent of the respondents were administered a more detailed questionnaire B.

Questionnaire B respondents were asked to describe their activities in their own words, and these were post-coded into 108 different activities. Only questionnaire B allows an exploration of different domestic tasks, so our analysis is limited to questionnaire B respondents.

Both UKTUS and STULA surveys collected information about individuals' time use, along with a range of social, economic, and demographic variables. Time use surveys, utilising time-diary instruments, yield reliable estimates of the time individuals spend in different activities throughout the day, providing critical insights into daily activities (Kan \& Pudney, 2008). Having identified time use activities relevant to unpaid work from UKTUS and STULA we harmonised them into 19 activities. These 19 activities are cooking, washing dishes, making textiles, laundry, gardening, pet care, shopping, home maintenance, car maintenance, service use, household management, other housework, physical care of a child, teaching a child, interacting with a child, accompanying a child, escorting a child, and care for an adult. They are further grouped into 9 broader activities as shown in Table 2. Note that in both UKTUS and STULA, these 19 activities are recorded either as a main activity or a simultaneously conducted secondary activity in each time slot. We included both the main and the secondary activities when counting individuals' time use on unpaid work. 